\title{
Hemodialysis (HD) dose and ultrafiltration rate are associated with survival in pediatric and adolescent patients on chronic HD-a large observational study with follow-up to young adult age
}

\author{
Verena Gotta ${ }^{1}$ (D) $\cdot$ Olivera Marsenic $^{2} \cdot$ Andrew Atkinson $^{1} \cdot$ Marc Pfister $^{1,3}$ \\ Received: 24 August 2020 /Revised: 19 January 2021 / Accepted: 27 January 2021 / Published online: 2 March 2021 \\ (C) The Author(s) 2021
}

\begin{abstract}
Background Hemodialysis (HD) dose targets and ultrafiltration rate (UFR) limits for pediatric patients on chronic HD are not known and are derived from adults ( $\mathrm{spKt} / \mathrm{V}>1.4$ and $<13 \mathrm{ml} / \mathrm{kg} / \mathrm{h}$ ). We aimed to characterize how delivered HD dose and UFR are associated with survival in a large cohort of patients who started HD in childhood.

Methods Retrospective analysis on a cohort of patients $<30$ years, on chronic HD since childhood ( $<19$ years), having received thrice-weekly HD 2004-2016 in outpatient DaVita centers. Outcome: Survival while remaining on HD. Predictors: (I) primary analysis: mean delivered dialysis dose stratified as spKt/V $\leq 1.4 / 1.4-1.6 />1.6$ (Kaplan-Meier analysis), (II) secondary analyses: UFR and alternative dialysis adequacy measures $[\mathrm{eKt} / \mathrm{V}$, body-surface normalized $\mathrm{Kt} / \mathrm{BSA}$ ] on continuous scale (Weibull regression model).

Results A total of 1780 patients were included (age at the start of HD: $0-12 \mathrm{y}: n=321,>12-18 \mathrm{y}: n=1459$; median spKt/V=1.55, $\mathrm{eKt} / \mathrm{V}=1.31, \mathrm{Kt} / \mathrm{BSA}=31.2 \mathrm{~L} / \mathrm{m}^{2}, \mathrm{UFR}=10.6 \mathrm{~mL} / \mathrm{kg} / \mathrm{h}$ ). (I) $\mathrm{spKt} / \mathrm{V}<1.4$ was associated with lower survival compared to spKt/V $>1.4-1.6(P<0.001$, log-rank test), and spKt/V>1.6 $(P<0.001)$, with 10-year survival of $69.3 \%(59.4-80.9 \%)$ versus $83.0 \%$ (76.8-89.8\%) and 84.0\% (79.6-88.5\%), respectively. (II) $\mathrm{Kt} / \mathrm{BSA}$ was a better predictor of survival than spKt/V or eKt/V. UFR was additionally associated with survival $(P<0.001)$, with increased mortality $<10 />18 \mathrm{~mL} / \mathrm{kg} / \mathrm{h}$. Associations did not alter significantly following adjustment for demographic characteristics (age, etiology of kidney disease, and ethnicity).

Conclusions Our results suggest usefulness of targeting Kt/BSA $>30 \mathrm{~L} / \mathrm{m}^{2}$ for best long-term outcomes, corresponding to $\mathrm{spKt} / \mathrm{V}>1.4$ ( $>12$ years) and $>1.6$ ( $<12$ years). In contrast to adults, higher UFR of $10-18 \mathrm{ml} / \mathrm{kg} / \mathrm{h}$ was not associated with greater mortality in this population.
\end{abstract}

Keywords Hemodialysis $\cdot$ Survival $\cdot$ Adequacy $\cdot \mathrm{Kt} / \mathrm{V} \cdot$ Body surface area $\cdot$ Ultrafiltration

\section{Introduction}

Hemodialysis (HD) dose targets for adults have been defined in terms of small solute clearance, currently considered the best measure of $\mathrm{HD}$ adequacy [1]. It is measured using urea kinetics during $\mathrm{HD}$ as reference solute, with a target of $\mathrm{spKt} / \mathrm{V}>1.4$ and

Verena Gotta

verena.gotta@ukbb.ch

1 Pediatric Pharmacology and Pharmacometrics, University of Basel Children's Hospital, Spitalstrasse 33, 4031 Basel, Switzerland

2 Pediatric Nephrology, Stanford University School of Medicine, Lucile Packard Children's Hospital, Stanford, CA, USA

3 Certara, Princeton, NJ, USA minimum of 1.2 defined (with $\mathrm{sp}=$ single pool urea distribution model, $\mathrm{K}=$ urea clearance, $\mathrm{t}=$ treatment time, $\mathrm{V}=$ urea distribution volume [2]). Studies in adults have shown a correlation between low spKt/V and increased mortality [3, 4], while higher than target spKt/V has not been associated with improved survival in adults [5]. Concerning fluid removal during $\mathrm{HD}$, ultrafiltration rates (UFR) $>10-13 \mathrm{~mL} / \mathrm{kg} / \mathrm{h}(>1.0-1.3 \%$ per $\mathrm{kg}$ per hour) have been associated with mortality in adults [6].

The significance of these findings remains unclear for children on chronic HD, as small patient numbers limit systematic clinical investigations in this population. Small solute clearance targets are generally adopted from adults in the absence of pediatric studies [7]. However, children may require higher $\mathrm{spKt} / \mathrm{V}$ targets, due to higher urea rebound $[8,9]$ and a higher ratio of body surface area (BSA) to body weight compared to adults, linked to higher metabolic rate. Hence, alternative 
metrics of urea clearance may be favored, such as equilibrated $\mathrm{eKt} / \mathrm{V}(\mathrm{eKt} / \mathrm{V})$ or BSA-normalized Kt/BSA [10-13]. While well investigated in adults, the UFR effect on pediatric outcomes has not yet been studied despite concerns that high UFR increases the risk of cardiovascular mortality [6]. High UFR is not uncommon in children [14] and is driven by nutritional needs of growing pediatric HD patients. This may be worrisome [15] given that prescribed UFR is closely related to interdialytic weight gain (IDWG), which has been associated with left ventricular hypertrophy at IDWG $>4 \%[16]$ and preHD hypertension [17] in children. Yet, there are no studies of the UFR effect on outcomes in this population. In the absence of outcome data, fluid removal in children has been proposed to be limited to $1.5 \pm 0.5 \%$ of body weight per hour (max. $5 \%$ during one session) [18].

Here we report the first study investigating the relationship between HD dose, UFR, and survival in a large pediatric cohort on thrice-weekly HD [19]. Our objectives were to evaluate (I) the association between spKt/V (stratified as low: $\leq 1.4$, target: 1.4-1.6, high: $>1.6$ ) and survival while remaining on $\mathrm{HD}$, (II) to compare the association of different small solute clearance metrics (spKt/V, eKt/V, Kt/BSA) with survival on a continuous scale, and (III) to evaluate the effect of fluid balance indices (UFR and associated IDWG) on survival.

\section{Methods}

\section{Study design and participants}

Data used for this retrospective analysis originate from an observational cohort of patients who started chronic HD in childhood ( $\leq 19$ years), with a maximum follow-up until $<30$ years of age, having received standardized thriceweekly HD between $05 / 2004$ and $03 / 2016$ in outpatient DaVita Kidney Care (DaVita Inc., Denver, CO, USA) dialysis centers $[9,14,19]$. The scientific use of the deidentified standardized electronic medical records was approved by DaVita (DaVita Clinical Research $®$, Minneapolis, MN); IRB approval was not required since retrospective analysis was performed on the deidentified dataset.

\section{Variables and measurement}

Age at the start of dialysis was calculated from treatment and first dialysis date (age in years recorded as integers). Further recorded baseline demographic factors potentially associated with mortality in stage 5 chronic kidney disease (CKD 5) patients $[20,21]$ included gender, etiology of kidney disease (e.g., secondary glomerulonephritis), and comorbidities (e.g., diabetes and connective tissue disease).

Dialysis dose in terms of $\mathrm{spKt} / \mathrm{V}$ and $\mathrm{eKt} / \mathrm{V}$ was calculated for each recorded treatment [2, 22]. Three alternative dialysis adequacy markers normalized by weight $^{0.67}$, weight ${ }^{0.75}$, and BSA, respectively $\left(\mathrm{Kt} / \mathrm{W}^{0.67}\right.$, $\mathrm{Kt} / \mathrm{W}^{0.75}, \mathrm{Kt} / \mathrm{BSA}$ ), were calculated [13]:

$\mathrm{Kt} / \mathrm{W}^{0.67}=\mathrm{spKt} / \mathrm{V} \cdot \mathrm{V}_{\mathrm{TBW}} / \mathrm{W}^{0.67}$

$\mathrm{Kt} / \mathrm{BSA}=\mathrm{spKt} / \mathrm{V} \cdot \mathrm{V}_{\mathrm{TBW}} / \mathrm{BSA}$

where $\mathrm{V}_{\mathrm{TBW}}=$ total body water $(\mathrm{L})$ according to Cheek [23, 24] or Watson [25], respectively (assumed to equal urea distribution volume V), BSA = BSA according to Mosteller [26], and $\mathrm{W}=$ target dry weight $(\mathrm{kg})$.

Fluid removal in terms of UFR $(\mathrm{mL} / \mathrm{kg} / \mathrm{h})$ and total ultrafiltration (UF, \% per kg dry weight per session) was derived for each treatment from pre- and postdialytic weight and treatment duration. Interdialytic weight gain (IDWG) was derived from post- and predialytic weight difference of subsequent treatments and was expressed as \%increase per kg dry weight over 2 days [17].

For each patient, mean individual values of $\mathrm{spKt} / \mathrm{V}, \mathrm{eKt} / \mathrm{V}$, $\mathrm{Kt} / \mathrm{W}^{0.67}, \mathrm{Kt} / \mathrm{W}^{0.75}, \mathrm{Kt} / \mathrm{BSA}$, UFR, UF, and IDWG during follow-up on HD were calculated for further analysis; no minimum repeated observation number was defined for this calculation.

\section{Primary outcome}

The primary outcome of interest was overall survival while remaining on $\mathrm{HD}$ (death from any cause) stratified by dialysis dose (spKt/V $\leq 1.4$ / 1.4-1.6 / >1.6). As supplementary analyses, the same outcome was investigated within two agegroups at the start of dialysis $(0-12 />12-19$ years $)$, and relative survival (hazard ratio) was investigated adjusted for age and other potentially relevant demographic characteristics (gender, etiology of kidney disease, ethnicity, and comorbidities), considering potential interactions with age at the start of HD.

\section{Secondary outcome}

The secondary outcome of interest was absolute survival while remaining on HD as a continuous function of dialysis dose (measured as spKt/V, eKt/V, Kt/W $\mathrm{W}^{0.67}, \mathrm{Kt} / \mathrm{W}^{0.75}$, or $\mathrm{Kt} /$ BSA), fluid balance (UFR, UF, or IDWG), and other potentially relevant demographic characteristics, considering potential interactions with age at the start of HD.

\section{Statistical methods}

Given the low number of patients with follow-up $>15$ years and the maximal age during follow-up of 29 years (resulting in a maximal follow-up period of 10 years in patients starting dialysis with 19 years), later observations were censored at 15 years. The primary outcome analysis included all patients for 
whom duration of follow-up on HD was recorded with information on spKt/V and age, whereas supplementary and secondary outcome analyses were performed on complete-case data with respect to further potentially relevant demographic characteristics. Patients lost to follow-up (e.g., due to transplantation, ongoing HD treatments > 03/2016 (date of data extraction), discharge to other facility (details Table 1)) were censored at their last observation.

The primary outcome was investigated using nonparametric methods (Kaplan-Meier). The log-rank test was used to compare survival on HD between subgroups where KaplanMeier curves suggested a difference between any two of the spKt/V groups. Survival probabilities were derived with $95 \%$ confidence intervals at 5, 10, and 15 years. In a supplementary analysis of the primary outcome, Kaplan-Meier curves were generated for age groups $</>12$ years at the start of HD, and relative survival for the spkt/V strata was evaluated by fitting both the univariable and multivariable parametric Weibull proportional hazards models. Multivariable models were adjusted for potential confounders (demographic characteristics). The appropriateness of the Weibull distribution for the baseline hazard function was evaluated by comparing the predicted survival curve of the null model (without covariates) with the corresponding nonparametric Kaplan-Meier survival curve. The proportional hazard assumption was verified visually, using the $\log$ (time) vs. $\log (-\log$ (survival(time) $)$ plot and the Schoenfeld residuals.

Absolute survival as a continuous function of dialysis adequacy measures and fluid balance indices (secondary outcomes) was investigated by fitting a Weibull accelerated failure time model. Covariates were included in the adjusted model by considering linear, log-linear, quadratic, and cubic relationships. The best covariate relationship was chosen based on visual agreement of the corresponding predicted $\log$ hazard function with the one predicted using a smoothing spline, the Akaike information criterion, and $P$ value from the likelihood ratio test (LRT) compared to the null model. Variables with a $P$ value $<0.05$ (LRT) in univariable analyses were further considered for the multivariable adjusted analysis. Among the variables referring to a metric of dialysis adequacy (spKt/V, eKt/V, Kt/W $\mathrm{W}^{0.67}, \mathrm{Kt} / \mathrm{W}^{0.75}, \mathrm{Kt} / \mathrm{BSA}$ ) or fluid balance (UFR, UF, IDWG), only the variable with the lowest $P$ value was used for forward selection and backward deletion considering further demographic baseline characteristics.

Based on initial findings, the following post hoc subgroup and sensitivity analyses were performed. For the primary outcome: (a) censoring all patients at 19 years of age, (b) stratification of age group $\leq 12$ years into $<6$ years and $6-12$ years at the start of HD; and (c) piece-wise analysis the first 2 years versus $\geq 2$ years to investigate the potential magnitude of timevarying hazard (visual investigation suggested potential nonproportionality within the first 2-3 years, although the test for proportional hazards indicated no violation of this assumption). With regard to the secondary outcome: (a) censoring all patients at 19 years of age, (b) for covariates retained in the multivariate model, Kaplan-Meier curves were used as a goodness-of-fit comparison, stratifying the variable of interest into quartiles. (c) The correlation between $\mathrm{Kt} / \mathrm{BSA}$ and spKt/V was investigated stratified by gender and age, to determine $\mathrm{Kt} / \mathrm{BSA}$ values that would correspond to target spKt/ $\mathrm{V}$ of 1.4-1.6 associated with good survival in adolescent patients. (d) Correlations between disease-related mortality risk factors [27] with investigated dialysis adequacy measures and fluid balance indices were investigated by the Spearman rank correlation coefficient.

Throughout a $P$ value of less than 0.05 was considered statistically significant. All analyses, figures, and statistics were generated in $\mathrm{R}$ version 3.6.2.

\section{Results}

\section{Patients and available predictor variables}

From the 1852 patients with in total 53,903 treatment records with spKt/V evaluation (having mainly been performed monthly, median: 16, IQR: 5-43 per patient) previously reported [19], a total of 1780 patients (52,083 HD treatment records with $\mathrm{spKt} / \mathrm{V}$ evaluation) had their duration and follow-up on HD documented for the primary analysis ( $n$ $=321$ having started HD at 0-12 years of age, $n=$ 1459 at > 12-19 years). Among these, $1493(83.9 \%)$ had complete baseline characteristic data and were included in adjusted analyses (Table 1).

\section{Primary outcome}

The Kaplan-Meier survival curve while remaining on HD stratified by mean delivered spKt/V is shown in Fig. 1 (primary endpoint). Survival was significantly lower in patients with low spKt/V $\leq 1.4$ compared to patients with target spKt/ $\mathrm{V}>1.4-1.6$ (log-rank test $P<0.001)$ and compared with high spKt $/ \mathrm{V}>1.6(P=0.002)$ but did not differ between patients treated with target versus high $\operatorname{spKt} / \mathrm{V}(P=0.5)$. Survival estimates at 5-15 years are provided in Table 2 .

Within the group of patients starting HD at 0-12 years of age (Fig. 2A), lower survival was suggested with target spKt/ $\mathrm{V}>1.4-1.6$ compared to high $\mathrm{spKt} / \mathrm{V}>1.6$, but this was not statistically significant $(P=0.2)$. No further comparisons were made with low spKt $/ \mathrm{V}<1.4$ due to small patient numbers. For the group of patients starting HD $>12-19$ years (Fig. 2B), low $\mathrm{spKt} / \mathrm{V}<1.4$ was associated with lower survival compared to target spKt $/ \mathrm{V}>1.4-1.6(P<0.001)$ and high spKtV $>1.6(P=$ $0.004)$. There was no significant difference between high spKtV > 1.6 and target $\mathrm{spKt} / \mathrm{V}>1.4-1.6(P=0.09)$. The subgroup analysis performed within age group $\leq 12$ years 


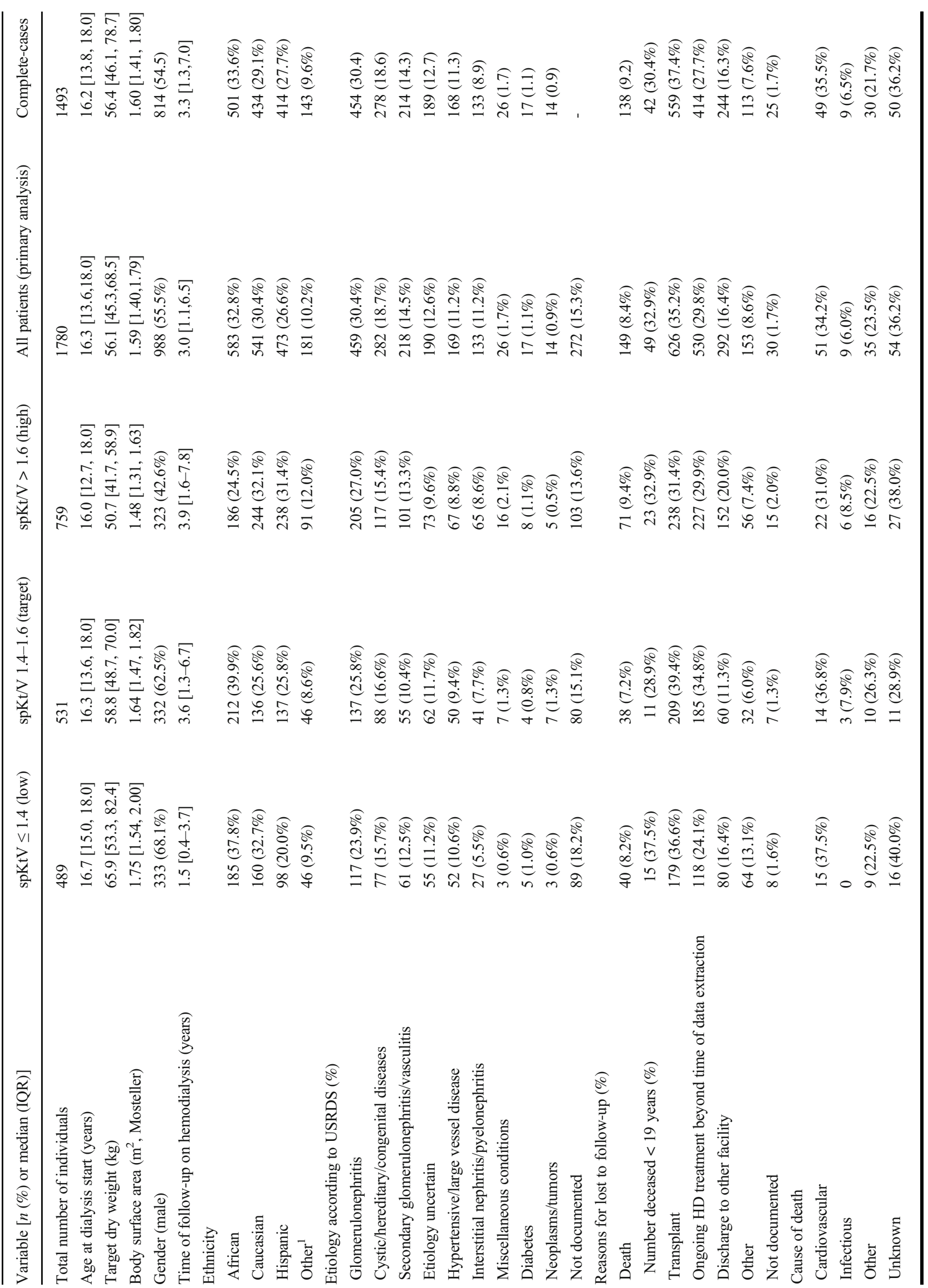




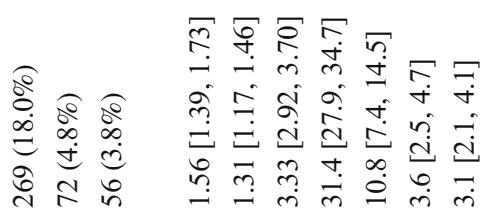

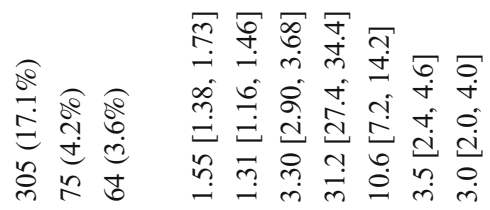

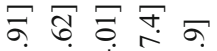

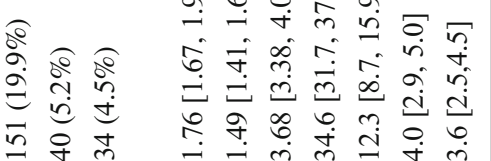

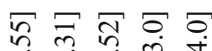

ब $\approx$ के

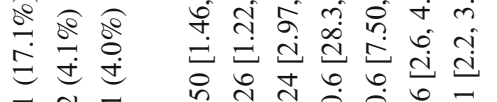

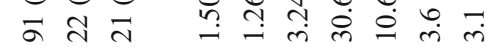

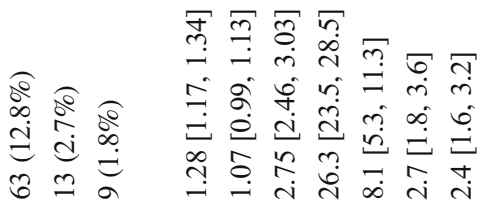

寻 $>$ 击

要表芆

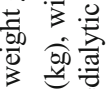

营范

震

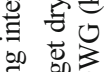

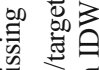

青它

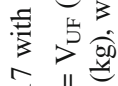

II 11

宅

㝵

证

昜要求

傿

壱焉年

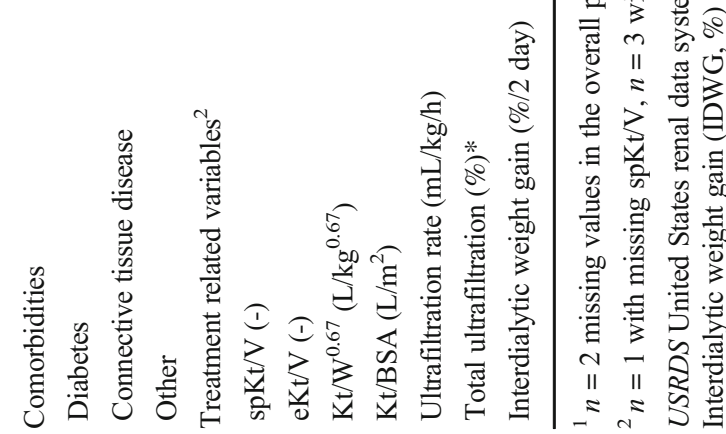




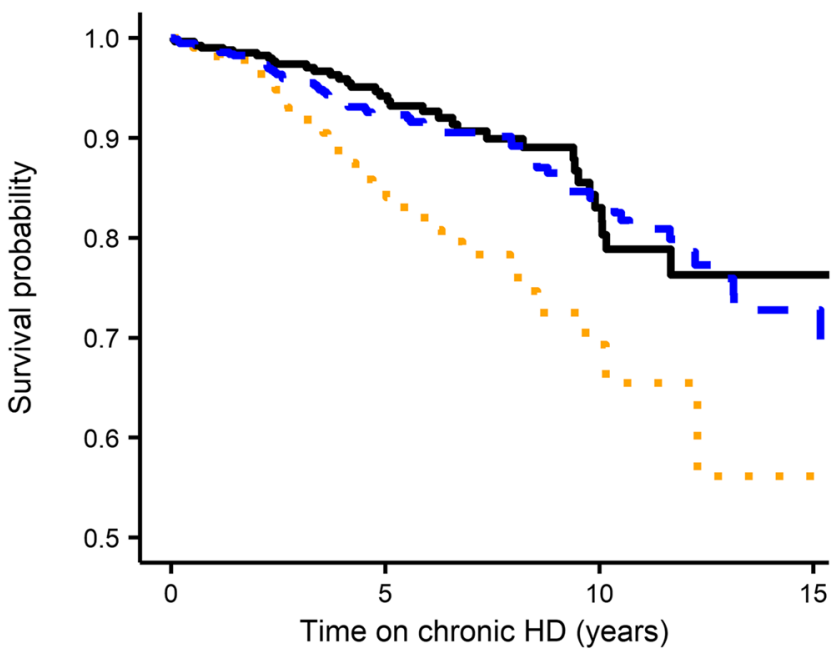

numbers at risk (by spKt/V)

$\begin{array}{rrccc}<=1.4 & 489 & 91 & 18 & 3 \\ >1.4-1.6 & 531 & 197 & 63 & 8 \\ >1.6 & 759 & 310 & 118 & 22\end{array}$

Fig. 1 Survival probability while remaining on chronic hemodialysis (Kaplan-Meier curve) by mean spKt/V delivered (primary outcome); log-rank test: $\mathrm{spKtV} \leq 1.4$ (dotted) versus $>1.4-1.6$ (solid): $P=$ 0.0007 . $\mathrm{spKtV} \leq 1.4$ versus $>1.6$ (dahsed): $P=0.002$

did not show statistical significance of mean $\mathrm{spKt} / \mathrm{V}$ within the subgroups $<6$ years and 6-12 years at the start of HD (Online Resource Fig. S1).

A Weibull model captured the form of the baseline hazard well, with 5-, 10- and 15-year predictions within the $95 \%$ confidence interval of the Kaplan-Meier curve (red line, Online Resource Fig. S2A). The corresponding estimated scale and shape parameters of the baseline hazard function were $\sigma=35.4$ years (time when predicted survival $=40 \%$ ) and $\alpha=1.23$ (indicating with $\alpha>1$ increasing hazard of death over time). The estimated hazard ratio (HR) from the unadjusted Weibull proportional hazards model indicated an increased risk for low versus target $\mathrm{spKt} / \mathrm{V}(\mathrm{HR}=2.3,95 \% \mathrm{CI}$ : [1.4-3.6], $P<0.001)$, but there was no discernable difference between target and high spKt/V (HR $=1.05$, [0.69-1.61], $P=$ $0.804)$. These estimates did not alter significantly $(\mathrm{HR}=2.3$ for low versus target spKt/V, $P<0.001 ; \mathrm{HR}=1.2$ for high versus target $\mathrm{spKt} / \mathrm{V}, P=0.44$ ) following adjustment for age $(\mathrm{HR}=0.66$ for $<12$ years compared to $12-19$ years, $P=0.09$ ), etiology $(\mathrm{HR}=2.5$ for secondary glomerulonephritis, $P<$ 0.001; other etiologies did not show significant associations) and ethnicity $(\mathrm{HR}=1.5$ for African origin, $P=0.025)$. An interaction of $\mathrm{spKt} / \mathrm{V}$ with age was observed that was significant for high spKt $/ \mathrm{V}>1.6(\mathrm{HR}=0.32$ for age $<12$ years, $P=$ $0.03)$, but not in the reference group treated with target spKt $/ \mathrm{V}$ $(P=0.35)$ or in the low dose group $\leq 1.4(P=0.19)$ (Online Resource Fig. S3).

The association shown in Fig. 1 did not change when including patients only up to 19 years of age in the analysis (Online Resource Fig. S4A). Investigation of Kaplan-Meier curves on $\log ($ time $)$ versus $\log (-\log (\mathrm{S}(\mathrm{t})))$ scale (Online Resource Fig. S2B) and visual inspection of the Schoenfeld residuals did not indicate any clear deviation from proportional hazard assumption. Nevertheless, the post hoc sensitivity analysis considering piece-wise survival showed that spKt/V was not significantly associated with survival within the first 2 years (adjusted $\mathrm{HR}=1.9$ for low versus target $\mathrm{spKt} / \mathrm{V}, P=$ 0.18). The estimated adjusted HR for the subgroup of patients with follow-up of at least 2 years $(n=975)$ was $2.4(P=0.002)$ for low versus target $\mathrm{spKt} / \mathrm{V}$.

\section{Secondary outcome}

The association of investigated covariates with absolute survival from the Weibull accelerated failure time (AFT) regression model is shown in Fig. 3, ordered by covariate importance ( $P$ value of LRT). Kt/BSA showed a stronger association with survival $(P<0.001$, linear and log-linear relationships, using $\mathrm{V}_{\text {TBW }}$ according to Cheek et al. [23, 24]) compared to other metrics of dialysis adequacy, and in particular, compared with spKt/V and eKt/V $(P<0.001$, log- and linear relationship). Indices of fluid balance were nonlinearly related with survival; the strongest association was found for UFR $(P<0.001$, quadratic relationship). Age at the start of dialysis was also associated with survival $(P<0.001$, cubic relationship; $P=0.001$, linear relationship). The relationship
Table 2 Observed overall survival (95\% confidence interval) while remaining on hemodialysis

\begin{tabular}{lllll}
\hline & Number & 5 years & 10 years & 15 years \\
\hline $\begin{array}{l}\text { All patients (primary outcome) } \\
\text { by spKt/V }\end{array}$ & 1780 & $91.6(89.8-93.4)$ & $81.4(77.9-85.0)$ & $70.9(65.1-77.2)$ \\
$\leq 1.4$ & 489 & $85.0(79.6-90.7)$ & $69.3(59.4-80.9)$ & $56.1(39.2-30.3)$ \\
$>1.4-1.6$ & 531 & $94.1(91.5-96.9)$ & $83.0(76.8-89.8)$ & $76.3(67.9-85.8)$ \\
$>1.6$ & 759 & $92.2(89.9-94.7)$ & $84.0(79.6-88.5)$ & $72.7(65.3-81.0)$ \\
Complete-cases ${ }^{1}$ & 1493 & $91.3(89.4-93.2)$ & $80.6(76.9-84.4)$ & $71.4(65.7-77.6)$ \\
Weibull null-model estimates & & 91.4 & 81.0 & 70.7 \\
\hline
\end{tabular}

\footnotetext{
${ }^{1}$ Used for estimation of adjusted hazard ratios and secondary outcome analysis in the Weibull regression model
} 


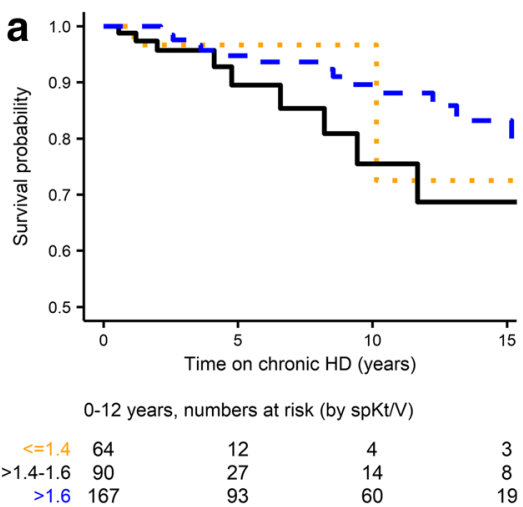

Fig. 2 Survival while remaining on chronic hemodialysis stratified by $\mathrm{spKt} / \mathrm{V}$ within age groups (Kaplan-Meier curve). a 0-12 years at the start of dialysis; log-rank test target (solid) versus high (dashed) spKtV (>1.4 1.6 versus $>1.6$ ): $P=0.2$ (ns). $\mathbf{b}>12-19$ years at the start of dialysis; log-

between these variables and model-predicted log-hazard is illustrated in Fig. 4. No interaction with age was apparent for $\mathrm{Kt} / \mathrm{BSA}$ or UFR. Among further baseline demographic factors, etiology (secondary glomerulonephritis) was most strongly associated with lower survival $(P<0.001)$, followed by age at the start of dialysis, connective tissue disease $(P=0.003)$, and African origin $(P=0.004)$. No association could be found for gender $(P=0.12)$ and diabetes as comorbidity $(P=0.94)$. In the sensitivity analysis (censoring patients at 19 years of age) similar associations were observed, while suggesting that the use of the Cheek equation (and not Watson) is particularly relevant $<$ 19 years of age for the strong log-linear relationship with $\mathrm{Kt} /$ BSA observed (Online Resource Fig. S4B).

In the multivariate analysis, Kt/BSA (log-linear), UFR (quadratic), age (linear), etiology, and ethnic origin were statistically significant following forward and backward selection (Estimates: Online Resource Table S1A). Parameter estimates for a cubic age relationship could not be estimated with good precision (Online Resource Table S1B) but provided better model predictions as evaluated by comparison with Kaplan-Meier plots. No interaction with age at the start of $\mathrm{HD}$ could be found. Correlation between $\mathrm{spKt} / \mathrm{V}$ and $\mathrm{Kt} /$ BSA stratified by age and gender is shown in Fig. 5A, illustrating that $\mathrm{Kt} / \mathrm{BSA}$ of $30-34 \mathrm{~L} / \mathrm{m}^{2}$ would correspond

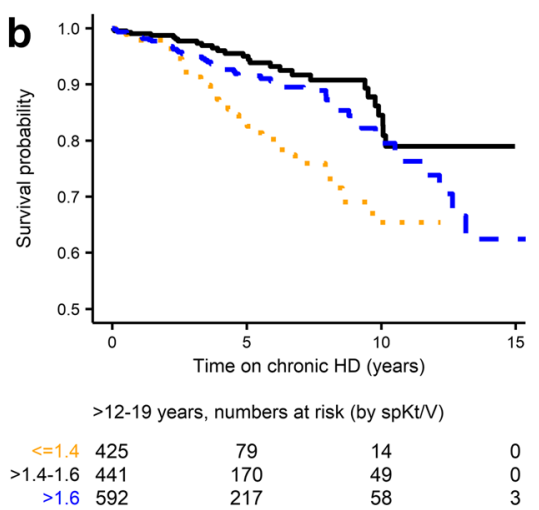

rank test low (dotted) versus target (solid) $\mathrm{spKtV}(\leq 1.4$ versus $>1.4-1.6)$ : $P<0.001$; and target (solid) versus high (dashed) spKtV (> 1.4-1.6 versus $>1.6): P=0.09$ (ns)

approximately to spKtV of 1.4-1.6 in adolescent boys, 1.61.8 in adolescent girls, and $>1.6$ in children $<12$ years $(\geq 1.8$ in the subgroup of children $<6$ years) (Fig. 5B). Predicted survival curves for the final multivariate model are illustrated for different $\mathrm{Kt} / \mathrm{BSA}$ and UFR values for a mean patient ( 15 years at the start of HD, etiology not secondary glomerulonephritis/vasculitis, ethnic origin not African American) in Fig. 6.

Correlations with previously identified disease-related mortality risk factors are depicted in Online Resource Fig. $\mathrm{S} 5$, showing no major correlation with main risk factors (maximal correlation of $\rho=0.12$ for albumin and $\rho=-0.28$ for lactate dehydrogenase with $\mathrm{Kt} / \mathrm{BSA}, \rho=0.09$ for red blood cell distribution width with UFR).

\section{Discussion}

This retrospective observational study is the first to demonstrate an association between low small solute clearance $(\mathrm{spKt} / \mathrm{V}<1.4)$ and a higher risk of mortality on long-term HD in patients having started HD in childhood (0-19 years, median: 16 years). To our knowledge, this patient cohort is uniquely the largest pediatric cohort studied receiving
Fig. 3 Summary of monovariate relationships tested, ordered by relative importance of each variable (lowest $P$ value according to likelihood ratio test, LRT) for the best fitting relationship. Black solid line: $P=$ 0.05 , black dashed line: $P=0.01$

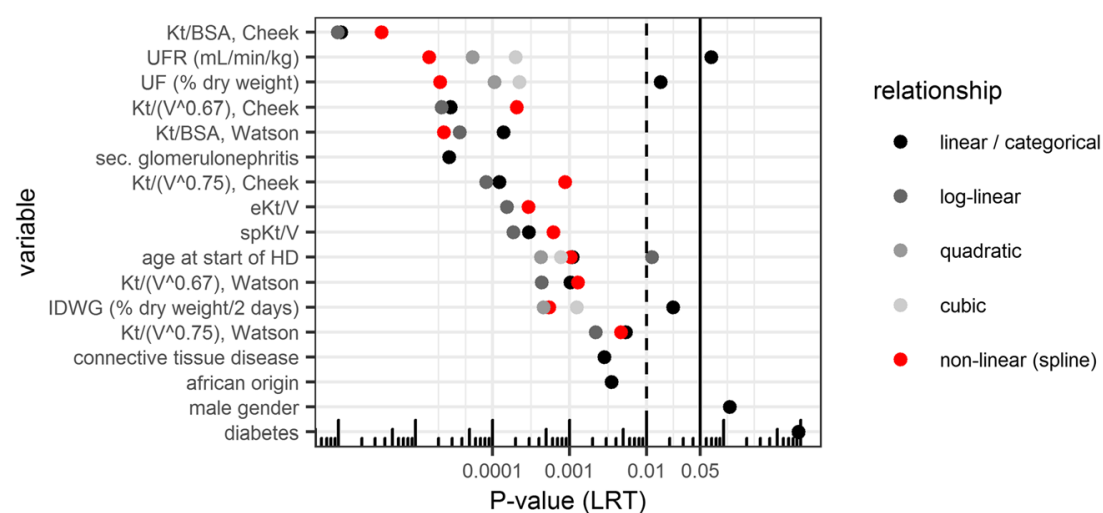



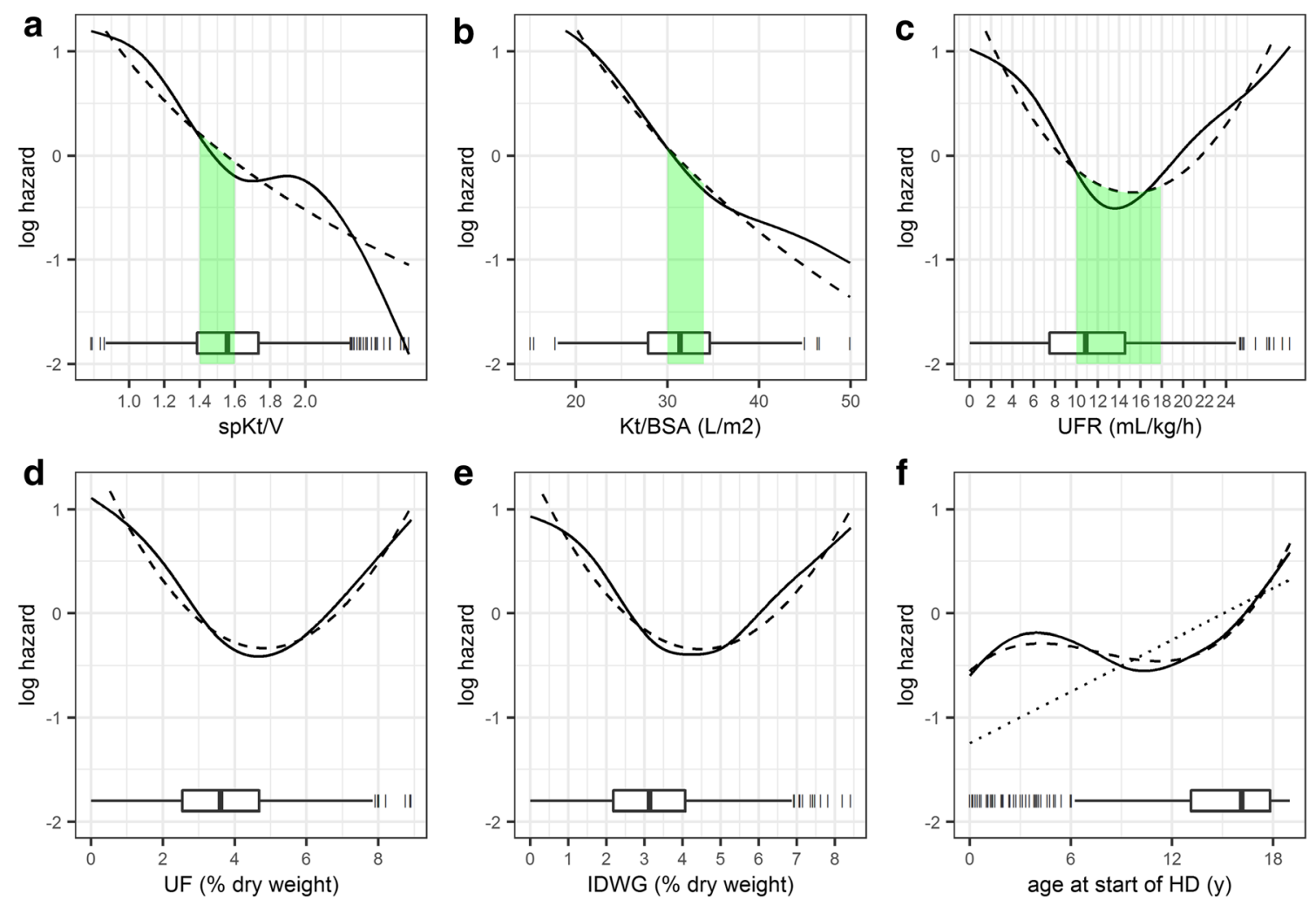

Fig. 4 Illustration of predicted log-hazard of monovariate models (centered to mean value of each presented covariate). Solid line: Prediction from flexible nonlinear spline model. Dashed line: Prediction from more simple parametrizations (Kt/BSA and $\mathrm{spKt} / \mathrm{V}$ : log-linear relationship; ultrafilration and interdialytic weight gain (IDWG): quadratic relationship; age: linear/cubic relationship (dashed line: cubic, dotted line: linear)). The variable distribution is illustrated in the bottom of each panel by standard boxplots, 3 values of $\mathrm{spKt} / \mathrm{V}$ and $\mathrm{Kt} / \mathrm{BSA}$ beyond limits of the panel are not illustrated for better visualization. Green shaded areas: $\mathrm{spKt} / \mathrm{V}$ reference target of 1.4-1.6, approximately corresponding Kt/BSA of $30-34 \mathrm{~L} / \mathrm{m}^{2}$ (see Fig. 5). UFR of $10-18 \mathrm{~mL} / \mathrm{kg} / \mathrm{h}$ associated with low harzard in both spline and simpler parametric model. standardized HD from the same provider, allowing detailed analysis of all HD treatment and laboratory data over time. There is limited data on survival for pediatric patients remaining on HD for more than 10 years with which to compare our results. Our 5-year survival rate of $91.6 \%$ may however be considered consistent with a previously reported 4-year survival rate of $92.3 \%$ in pediatric patients starting HD between 2007-2011 [28]. Compared to patients treated with target $\mathrm{spKt} / \mathrm{V}>1.4-1.6$, survival on chronic HD was 9-20\% lower after $5-15$ years, respectively. Additional benefit of high spKt/ $\mathrm{V}>1.6$ was suggested in patients starting $\mathrm{HD}<12$ years of age, but not in those starting HD as adolescents. Interestingly, the apparent age-dependent dose-response relationship disappeared when considering Kt/BSA (using pediatric $\mathrm{V}_{\mathrm{TBW}}$ calculated according to Cheek et al. [23, 24] for calculation) as the dialysis adequacy metric. Similar to prior reports in adults, $\mathrm{Kt} / \mathrm{BSA}$ further showed a stronger association with survival than spKt/V [29]. Previously not reported, fluid balance indices in our study showed a strong association with survival, with both low and very high UFR associated with an increased risk of mortality in this young population. Specifically, no clearly increased mortality risk was observed in the range of
$10-18 \mathrm{~mL} / \mathrm{kg} / \mathrm{h}$ (lowest risk in the range of 13-15 approximately), in contrast to observational findings in adults [6].

In adults, the increased mortality risk with UFR $>10-13$ $\mathrm{mL} / \mathrm{kg} / \mathrm{h}$ is possibly explained by higher incidence of intradialytic hypotension and associated risk of organ ischemia [28]. Increased UFR was not associated with reduced intradialytic blood pressure in our population (lowest intradialytic systolic blood pressure values rather tended to be higher in patients treated with high UFR; data not shown) suggesting that most patients hemodynamically tolerated high UFR. The frequent use of high UFR in our population [14] may hence reflect that children and young adults having started HD during childhood require higher fluid intake to meet nutritional needs and promote growth, and/or that they have better tolerance of high UFR. Increasing UFR for dry weight optimization can improve anemic and inflammatory control [29], with the added benefit of increased convective clearance of larger uremic solutes associated with cardiovascular disease and mortality [30]. The benefit of actively limiting UFR, especially without increasing treatment duration, has been questioned in adults: epidemiologically a $15 \%$ decrease in mean UFR during the recent years has not resulted in 

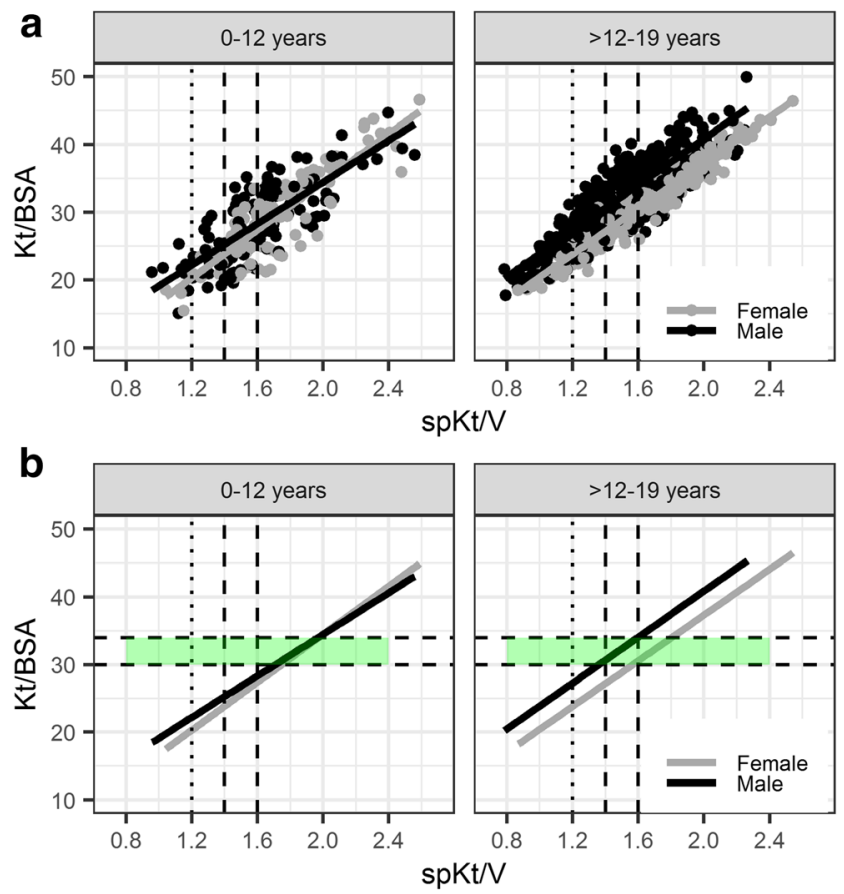

Fig. 5 Correlation between spKt/V and Kt/BSA stratified by age at the start of $\mathrm{HD}$ and gender (a: data with linear regression line illustrated, $\mathbf{b}$ : only linear regression line illustrated): $\mathrm{Kt} / \mathrm{BSA}$ translates to higher spKt $/ \mathrm{V}$ in younger $(0$ 12 years) and female patients ( $>12-19$ years), thus there is a risk of underdosing HD in these patients if same spKt/V is targeted for all. Dotted vertical line: minimum spKt/V of 1.2 targeted in adults. Dashed vertical lines: target spkt/V of $>1.4-1.6$. Horizontal dashed lines with green shaded area: $\mathrm{Kt} / \mathrm{BSA}$ of $30-34 \mathrm{~L} / \mathrm{m}^{2}$, corresponding approximately to spKtV of 1.4-1.6 in adolescent boys, $1.6-1.8$ in adolescent girls, and $>1.6$ in children $0-12$ years ( $\geq 1.8$ in the subgroup of children $<6$ years, data not shown separately).

reduced cardiovascular hospitalization rates [31]. Potentially worrisome, we observed a $40 \%$ decrease in UFR during our study period (from mean 12.2 to $7.3 \mathrm{~mL} / \mathrm{kg} / \mathrm{h}$ between 2004 and 2015, data not shown) in our population, while spKt/V prescriptions remained stable over time.

The association of low small solute clearance with a higher risk of mortality persisted after adjustment for baseline characteristics,

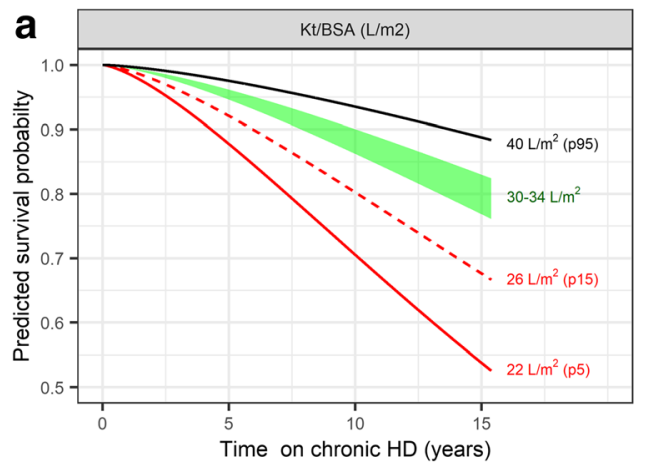

Fig. 6 Predicted survival from the fitted multivariate adjusted Weibull AFT model for different Kt/BSA and UFR for a mean reference patient of the population ( 15 years at the start of HD, etiology not secondary glomerulonephritis/vasculitis and ethnic origin not African American). Green shaded area: $\mathrm{Kt} / \mathrm{BSA}$ of $30-34 \mathrm{~L} / \mathrm{m}^{2}$ (percentiles p38 to $\mathrm{p} 71$ in including etiology of kidney disease (secondary glomerulonephritis), ethnicity (African origin), and older age at the start of HD. Connective tissue disease as a comorbidity was also associated with mortality in univariate analyses but not in multivariate analysis, probably due to its correlation with secondary glomerulonephritis/vasculitis. In contrast to previous reports [20], we could not demonstrate a significant association of mortality with female gender (though a trend toward better outcomes for male patients was observed in univariate analysis) or diabetes as comorbidity.

The relationship between age and survival on a continuous scale showed a relatively high mortality risk in those starting $\mathrm{HD}$ at 2-5 years of age, compared to those starting around 12 years of age, in line with the literature [20]. Within the adolescent age-group, we observed a risk increase with age, which is also consistent with USRDS data reporting higher mortality in patients initiating dialysis as young adults compared to children 0-19 years [21].

Evaluating spKt/V-age interactions (Fig. 2 and Fig. S3) indicated that decreasing survival in adolescents may be confounded by a larger proportion of adolescents being treated with belowtarget doses ( $\mathrm{spKt} / \mathrm{V} \leq 1.4)$ as compared to patients starting $\mathrm{HD}$ $<12$ years of age, while not benefitting from high spKt $/ \mathrm{V}>1.6$ as opposed to younger patients. We have previously reported agerelated differences in dialysis prescription in this population [19], in line with others [12], where we further found adolescents $\geq$ $100 \mathrm{~kg}$ of particular risk to receive low spKt/V [19]. The lack of benefit of higher spKt/V $>1.6$, particularly in adolescents, may be related to the different weight-BSA relationship (and hence $\mathrm{spKt} / \mathrm{V}-\mathrm{Kt} / \mathrm{BSA}$ relationship). This has been pointed out by others $[12,13]$, and may be compensated by benefits of longer treatment duration in obese adolescents (potentially associated with improved treatment of overhydration and clearance of time-dependent solutes) [30]. Interestingly, our spKt/ $\mathrm{V}-\mathrm{Kt} /$ BSA relationship observed in adolescents is consistent with the relationship for adults [13], while Kt/BSA is, as expected, lower in younger patients for a given spKt/V. We found that $\mathrm{Kt} / \mathrm{BSA}$ of $>30 \mathrm{~L} / \mathrm{m}^{2}$ corresponded approximately to $\mathrm{spKtV}$ of $>1.4$ in

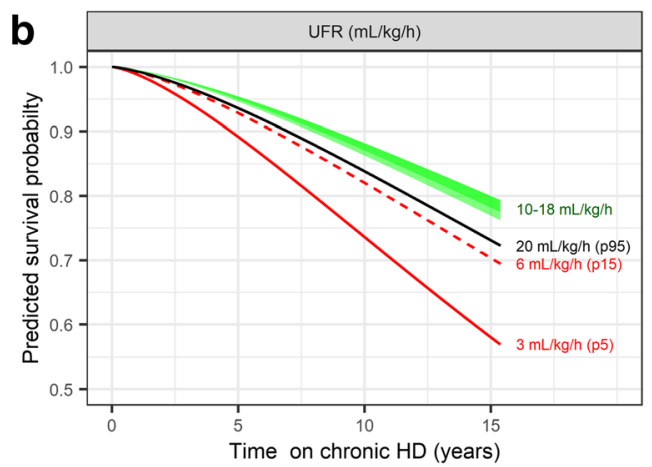

the population, see Fig. 4), corresponding approximately to spKtV of $1.4-1.6$ in adolescent boys, 1.6-1.8 in adolescent girls and $>1.6$ in children $<12$ years (see Fig. 5). UFR of $10-18 \mathrm{~mL} / \mathrm{kg} / \mathrm{h}$ (percentiles $\mathrm{p} 43$ to p92 in the population, see Fig. 4) is associated with lower risk in parametric models. 
adolescent boys (as reported for male adults [13]), > 1.6 in adolescent girls (in line with female adults [13]) and children $<12$ years $(\geq 1.8$ in children $<6$ years, data not shown separately). This observation may also support the finding that adult women benefit from higher spKt/V compared to men [5].

Results are consistent with a previous exploratory machinelearning based analysis on a subgroup of patients [27], suggesting optimal spKt $/ \mathrm{V}>1.5$ and UFR $>10 \mathrm{~mL} / \mathrm{kg} / \mathrm{h}$ for an average adolescent patient. In the present analysis, we did not investigate relationships of survival with other disease-related risk factors of mortality, such as albumin, lactate dehydrogenase, and red blood cell distribution width. In our supplementary analysis, we could not identify strong correlations with those variables, suggesting little risk of confounding by those variables. It also suggests that those disease-related variables are only marginally affected by HD treatment, stressing the importance of other intervention strategies to improve patient survival and well-being, e.g., related to treatment of nutrition and anemia. Some stronger correlation with z-score weight for age and normalized protein catabolic rate with investigated treatmentrelated variables could be observed. This deserves further investigation, as we have observed suboptimal growth particularly in patients $<12$ years of age [19], and as others have reported improved growth in children treated with more intense (longer or more frequent) dialysis [31, 32].

As we report on observational data, shown associations must be interpreted with caution regarding causality. It may be emphasized in this context that presented survival probabilities refer to "survival on chronic HD", and not to "overall survival", as no information on survival after kidney transplantation or facility discharge was available. As a cross check, we also performed a post hoc supplementary analysis taking into account transplantation as a competing risk (instead of random censoring). The results were consistent with the primary analysis, albeit the long-term survival probability was higher than in the presented analysis considering transplantation as a censoring event (Online Resource Fig. S6). We did not further investigate the influence of intraindividual variation in UFR or spKt/ $\mathrm{V}$ prescription, which was higher for UFR (average intraindividual variation: $\pm 48 \%$ or $\pm 5 \mathrm{~mL} / \mathrm{kg} / \mathrm{h}$ ) than for spKt/ $\mathrm{V}( \pm 15 \%$ or \pm 0.24$)$. Proposed Kt/BSA reference ranges may not apply to children and infants $<2$ years, in whom BSAnormalized healthy glomerular filtration rate is lower than in older patients [33]. Our ability to investigate age-dependent associations was partly limited by small patient numbers $<12$ years (and especially $<6$ years) of age. The trend toward lower association with spKt/V during the first two years of HD could be related to residual kidney function (RKF). RKF was not evaluated systematically in all patients but was reported only in a small percentage of patients (4\%) [19]. It is unlikely to have a significant effect on our long-term results as RKF tends to be lost in the majority of patients within the first year of starting HD on a thrice-weekly regimen [34]. In such cases, we would however expect better survival than observed in those patients. Although relatively high UFR in children of $10-18 \mathrm{ml} / \mathrm{kg} / \mathrm{h}$ appears to be risk-free regarding their survival, that may only be true if clinically well tolerated (as suggested from its frequent use in the presented population in the outpatient setting [14]), if associated with improved nutrition (as suggested from positive correlation of $\rho=0.41$ between UFR and normalized protein catabolic rate in Fig. S4), and if necessary, to achieve or optimize dry weight. Potentially negative (i.e., myocardial stunning) or positive (i.e., decreased chronic fluid retention) effects of high UFR on the cardiovascular system could not be assessed in our study. Previously recommended and historically well-tolerated fluid removal rate in children is reported to be up to $8 \%$ of body weight [35]. If $18 \mathrm{~mL} / \mathrm{kg} / \mathrm{h}$ UFR is used, in a $25 \mathrm{~kg}$ child, $1350 \mathrm{~mL}$ of fluid is removed in a $3 \mathrm{~h} \mathrm{HD}$ session, corresponding to $\sim 5.4 \%$ of body weight. This is well under $8 \%$, supporting our finding that UFR of $10-18 \mathrm{ml} / \mathrm{kg} / \mathrm{h}$ appears risk free. As patients were treated in $>1000$ different clinical centers, we cannot exclude influence of regional differences in patient care [36], potentially limiting generalizability of results to regions other than the US. However, all patients uniformly received treatment by the same dialysis provider, which resulted in standardized delivery, evaluation, and recording of HD treatment. This allowed us to perform an analysis of a uniquely large paediatric cohort over an extended period. As our analysis shows that mortality increases over time on dialysis, consistent with previous reports [37], the ultimate goal of early kidney transplantation remains undisputed.

In conclusion, observational findings from this first study in patients starting maintenance HD in childhood demonstrate the benefit of achieving spKt/V $>1.4$. Kt/BSA appears to be a clinically more meaningful marker of HD adequacy compared to $\mathrm{spKt} / \mathrm{V}$, supporting targeting higher $\mathrm{spKt} / \mathrm{V}$ in younger children. In children and adolescents requiring long-term hemodialysis, higher UFR of $10-18 \mathrm{~mL} / \mathrm{kg} / \mathrm{h}$ was associated with best survival, in contrast to data reported in adults. With the goal to improve long-term outcomes in pediatric $\mathrm{HD}$, we suggest that original findings reported here serve as guidance in HD dose and UFR prescription.

Supplementary Information The online version contains supplementary material available at https://doi.org/10.1007/s00467-021-04972-6.

Author contributions Conception and design: all; data analysis: VG and AA; data interpretation: all; drafting manuscript: VG, critically revising manuscript and approving final version: all.

Funding Open Access funding provided by Universität Basel (Universitätsbibliothek Basel). This project has been supported by the Research Fund for Junior Researchers, University of Basel, Switzerland, and by the Eckenstein-Geigy Foundation, which is sponsoring research at Pediatric Pharmacology at University Children's Hospital Basel. Part of the work has been presented as an abstract (oral communication) at ERA-EDTA 2019, Hungary. 
Data Availability The deidentified data used is owned by DaVita and cannot be shared by the authors.

Code availability Regression models are shared in detail in the Supplementary data with an example R-code that can be used for the Weibull model simulations.

\section{Declarations}

Ethics approval The scientific use of the deidentified standardized electronic medical records was approved by DaVita (DaVita Clinical Research ${ }^{\circledR}$, Minneapolis, MN); IRB approval was not required since retrospective analysis was performed on the deidentified dataset.

\section{Consent to participate/consent for publication Not applicable.}

Conflict of interest MP and OM are part-time consultants at Certara, Princeton, NJ, USA. AA is also employed at the Department of Infectious Diseases at Bern University Hospital, Switzerland. VG has nothing to disclose; all authors declare that they have no financial interests related to the manuscript.

Open Access This article is licensed under a Creative Commons Attribution 4.0 International License, which permits use, sharing, adaptation, distribution and reproduction in any medium or format, as long as you give appropriate credit to the original author(s) and the source, provide a link to the Creative Commons licence, and indicate if changes were made. The images or other third party material in this article are included in the article's Creative Commons licence, unless indicated otherwise in a credit line to the material. If material is not included in the article's Creative Commons licence and your intended use is not permitted by statutory regulation or exceeds the permitted use, you will need to obtain permission directly from the copyright holder. To view a copy of this licence, visit http://creativecommons.org/licenses/by/4.0/.

\section{References}

1. National Kidney Foundation (2015) KDOQI clinical practice guideline for hemodialysis adequacy: 2015 update. Am J Kidney Dis 66:884-930. https://doi.org/10.1053/j.ajkd.2015.07.015

2. Daugirdas JT (1993) Second generation logarithmic estimates of single-pool variable volume $\mathrm{Kt} / \mathrm{V}$ : an analysis of error. J Am Soc Nephrol 4:1205-1213

3. Lowrie EG, Laird NM, Parker TF, Sargent JA (1981) Effect of the hemodialysis prescription of patient morbidity: report from the National Cooperative Dialysis Study. N Engl J Med 305:11761181. https://doi.org/10.1056/NEJM198111123052003

4. Gotch FA, Sargent JA (1985) A mechanistic analysis of the National Cooperative Dialysis Study (NCDS). Kidney Int 28: 526-534

5. Eknoyan G, Beck GJ, Cheung AK, Daugirdas JT, Greene T, Kusek JW, Allon M, Bailey J, Delmez JA, Depner TA, Dwyer JT, Levey AS, Levin NW, Milford E, Ornt DB, Rocco MV, Schulman G, Schwab SJ, Teehan BP, Toto R, Hemodialysis (HEMO) Study Group (2002) Effect of dialysis dose and membrane flux in maintenance hemodialysis. N Engl J Med 347:2010-2019. https://doi. org/10.1056/NEJMoa021583

6. Flythe JE, Kimmel SE, Brunelli SM (2011) Rapid fluid removal during dialysis is associated with cardiovascular morbidity and mortality. Kidney Int 79:250-257. https://doi.org/10.1038/ki. 2010.383
7. Goldstein SL (2004) Prescribing and monitoring hemodialysis. In: Warady BA, Shaefer FS, Fine RN, Alexander SR (eds) Pediatric dialysis, 1st edn. Springer Science, Dordrecht, pp 135-145

8. Goldstein SL, Brem A, Warady BA, Fivush B, Frankenfield D (2006) Comparison of single-pool and equilibrated $\mathrm{Kt} / \mathrm{V}$ values for pediatric hemodialysis prescription management: analysis from the Centers for Medicare \& Medicaid Services Clinical Performance Measures Project. Pediatr Nephrol 21:1161-1166. https://doi.org/10.1007/s00467-006-0112-8

9. Gotta V, Marsenic O, Pfister M (2020) Understanding urea kinetic factors that enhance personalized hemodialysis prescription in children. ASAIO J 66(1):115-123. https://doi.org/10.1097/mat. 0000000000000941

10. Depner T, Daugirdas J, Greene T, Allon M, Beck G, Chumlea C, Delmez J, Gotch F, Kusek J, Levin N, Macon E, Milford E, Owen W, Star R, Toto R, Eknoyan G, Hemodialysis Study Group (2004) Dialysis dose and the effect of gender and body size on outcome in the HEMO Study. Kidney Int 65:1386-1394. https://doi.org/10. 1111/j.1523-1755.2004.00519.x

11. Daugirdas JT, Levin NW, Kotanko P, Depner TA, Kuhlmann MK, Chertow GM, Rocco MV (2008) Comparison of proposed alternative methods for rescaling dialysis dose: resting energy expenditure, high metabolic rate organ mass, liver size, and body surface area. Semin Dial 21:377-384. https://doi.org/10.1111/j.1525-139X. 2008.00483.x

12. Daugirdas JT, Hanna MG, Becker-Cohen R, Langman CB (2010) Dose of dialysis based on body surface area is markedly less in younger children than in older adolescents. Clin J Am Soc Nephrol 5:821-827. https://doi.org/10.2215/CJN.08171109

13. Spalding EM, Chandna SM, Davenport A, Farrington K (2008) Kt/ $\mathrm{V}$ underestimates the hemodialysis dose in women and small men. Kidney Int 74:348-355. https://doi.org/10.1038/ki.2008.185

14. Gotta V, Pfister M, Marsenic O (2019) Ultrafiltration rates in children on chronic hemodialysis routinely exceed weight based adult limit. Hemodial Int 23:126-128. https://doi.org/10.1111/hdi.12727

15. Fischbach M, Zaloszyc A, Shroff R (2015) The interdialytic weight gain: a simple marker of left ventricular hypertrophy in children on chronic haemodialysis. Pediatr Nephrol 30:859-863. https://doi. org/10.1007/s00467-015-3086-6

16. Paglialonga F, Consolo S, Galli MA, Testa S, Edefonti A (2015) Interdialytic weight gain in oligoanuric children and adolescents on chronic hemodialysis. Pediatr Nephrol 30:999-1005. https://doi. org/10.1007/s00467-014-3005-2

17. Marsenic O, Anderson M, Couloures KG (2016) Relationship between interdialytic weight gain and blood pressure in pediatric patients on chronic hemodialysis. Biomed Res Int 2016:5972930. https://doi.org/10.1155/2016/5972930

18. Fischbach M, Edefonti A, Schröder C, Watson A (2005) Hemodialysis in children: general practical guidelines. Pediatr Nephrol 20:1054-1066. https://doi.org/10.1007/s00467-0051876-y

19. Gotta V, Marsenic O, Pfister M (2018) Age- and weight-based differences in haemodialysis prescription and delivery in children, adolescents and young adults. Nephrol Dial Transplant 33:16491660. https://doi.org/10.1093/ndt/gfy067

20. Chesnaye NC, van Stralen KJ, Bonthuis M, Harambat J, Groothoff JW, Jager KJ (2018) Survival in children requiring chronic renal replacement therapy. Pediatr Nephrol 33:585-594. https://doi.org/ 10.1007/s00467-017-3681-9

21. Shroff R, Ledermann S (2009) Long-term outcome of chronic dialysis in children. Pediatr Nephrol 24:463-474. https://doi.org/10. 1007/978-1-4614-0721-8 33

22. Daugirdas JT, Schneditz $\bar{D}$ (1995) Overestimation of hemodialysis dose depends on dialysis efficiency by regional blood flow but not by conventional two pool urea kinetic analysis. ASAIO J 41:M719M724. https://doi.org/10.1097/00002480-199507000-00107 
23. Cheek DB, Mellits D, Elliott D (1966) Body water, height, and weight during growth in normal children. Am J Dis Child 112: 312-317

24. Morgenstern BZ, Mahoney DW, Warady BA (2002) Estimating total body water in children on the basis of height and weight: a reevaluation of the formulas of Mellits and Cheek. J Am Soc Nephrol 13:1884-1888

25. Watson PE, Watson ID, Batt RD (1980) Total body water volumes for adult males and females estimated from simple anthropometric measurements. Am J Clin Nutr 33:27-39

26. Mosteller RD (1987) Simplified calculation of body-surface area. $\mathrm{N}$ Engl J Med 317:1098-1098. https://doi.org/10.1056/ NEJM198710223171717

27. Gotta V, Tancev G, Marsenic O, Vogt JE, Pfister M (2021) Identifying key predictors of mortality in young patients on chronic haemodialysis - a machine learning approach. Nephrol Dial Transplant 36(3):519-528. https://doi.org/10.1093/ndt/gfaa128

28. Chesnaye N, Bonthuis M, Schaefer F, Groothoff JW, Verrina E, Heaf JG, Jankauskiene A, Lukosiene V, Molchanova EA, Mota C, Peco-Antić A, Ratsch IM, Bjerre A, Roussinov DL, Sukalo A, Topaloglu R, Van Hoeck K, Zagozdzon I, Jager KJ, Van Stralen KJ, ESPN/ERA-EDTA registry (2014) Demographics of paediatric renal replacement therapy in Europe: a report of the ESPN/ERAEDTA registry. Pediatr Nephrol 29:2403-2410. https://doi.org/10. 1007/s00467-014-2884-6

29. Lowrie EG, Li Z, Ofsthun N, Lazarus JM (2004) Measurement of dialyzer clearance, dialysis time, and body size: death risk relationships among patients. Kidney Int 66:2077-2084. https://doi.org/10. 1111/j.1523-1755.2004.00987.x

30. Davenport A (2013) Differences in prescribed Kt/V and delivered haemodialysis dose - why obesity makes a difference to survival for haemodialysis patients when using a "one size fits all" $\mathrm{Kt} / \mathrm{V}$ target. Nephrol Dial Transplant 28:iv219-iv223. https://doi.org/ $10.1093 / \mathrm{ndt} / \mathrm{gft} 237$
31. Tom A, McCauley L, Bell L, Rodd C, Espinosa P, Yu G, Yu J, Girardin C, Sharma A (1999) Growth during maintenance hemodialysis: impact of enhanced nutrition and clearance. J Pediatr 134: 464-471. https://doi.org/10.1016/S0022-3476(99)70205-2

32. Fischbach M, Terzic J, Menouer S, Dheu C, Seuge L, Zalosczic A (2010) Daily on line haemodiafiltration promotes catch-up growth in children on chronic dialysis. Nephrol Dial Transplant 25:867873. https://doi.org/10.1093/ndt/gfp565

33. Schwartz GJ, Work DF (2009) Measurement and estimation of GFR in children and adolescents. Clin J Am Soc Nephrol 4: 1832-1843

34. Mathew AT, Fishbane S, Obi Y, Kalantar-Zadeh K (2016) Preservation of residual kidney function in hemodialysis patients: reviving an old concept. Kidney Int 90:262-271. https://doi.org/10. 1016/j.kint.2016.02.037

35. Rees L, Schaefer F, Schmitt CP, Shroff R, Warady BA (2017) Chronic dialysis in children and adolescents: challenges and outcomes. Lancet Child Adolesc Health 1:68-77

36. Hussein R, Alvarez-Elías AC, Topping A, Raimann JG, Filler G, Yousif D, Kotanko P, Usvyat LA, Medeiros M, Pecoits-Filho R, Canaud B, Stuard S, Xiaoqi X, Etter M, Díaz-González de Ferris ME, MONDO Consortium (2018) A cross-sectional study of growth and metabolic bone disease in a pediatric global cohort undergoing chronic hemodialysis. J Pediatr 202:171-178.e3. https://doi.org/10.1016/j.jpeds.2018.07.033

37. McDonald SP, Craig JC (2004) Long-term survival of children with end-stage renal disease. N Engl J Med 350:2654-2662. https://doi. org/10.1056/NEJMoa031643

Publisher's note Springer Nature remains neutral with regard to jurisdictional claims in published maps and institutional affiliations. 